LETTERS

\title{
An unusual presentation of a common disease
}

\section{$M$ von Lilienfeld-Toal, S Merkelbach-Bruse, F L Dumoulin}

Ann Rheum Dis 2004;63:887-888. doi: 10.1136/ard.2003.013375

A variety of rheumatic syndromes have been associated with neoplasia. We report a case of occult metastatic breast cancer which presented with symptoms and signs of adult onset Still's disease (AOSD).

\section{CASE REPORT}

In July 2002, a 52 year old Caucasian woman presented with a 4 week history of high, spiking fevers (up to $40^{\circ} \mathrm{C}$ ) that were accompanied by a transient macular rash, myalgia, and arthralgia affecting most joints. Initially, there had been a sore throat and painful lymphadenopathy in the left supraclavicular fossa. A lymph node was removed for histopathological examination and the lymphadenopathy resolved spontaneously. The past medical history was unremarkable other than a family history of breast cancer which had affected two second degree relatives. The physical and gynaecological examinations were unremarkable. There was no peripheral lymphadenopathy. Blood tests showed a normochromic, normocytic anaemia (haemoglobin $100 \mathrm{~g} / \mathrm{l}$ ), a leucocytosis $(12.3 \mathrm{~g} / \mathrm{l} ; 85 \%$ neutrophils), raised $\mathrm{C}$ reactive protein (CRP; $91 \mathrm{mg} / \mathrm{l}$ ), and erythrocyte sedimentation rate (ESR; 94/120), an exceptionally high serum ferritin level (21 $762 \mu \mathrm{g} / \mathrm{l})$, abnormal liver function tests $(\gamma$-glutamyltransferase $105 \mathrm{U} / \mathrm{l}$, aspartate aminotransferase $32 \mathrm{U} / \mathrm{l}$ ), and lactate dehydrogenase (532 U/l). Testing for bacterial, viral, or fungal infection and autoantibody screens were consistently negative. Additional investigation (ultrasound, computed tomography scan, bone marrow aspirate) showed only splenomegaly and increased numbers of normal sized lymph nodes in the left axilla.

At that stage the clinical diagnosis of AOSD was made based on the presence of all the diagnostic criteria (fever, arthralgia, rash, leucocytosis as well as sore throat, lymphadenopathy, splenomegaly, liver dysfunction, and absence of rheumatoid factor and antinuclear antibody) proposed by Yamaguchi et al. ${ }^{1}$

Treatment was started with aspirin ( $3 \mathrm{~g} /$ day $)$ and this resulted in a gradual resolution of fever. To our surprise, the histopathological examination of the lymph node removed initially disclosed a small breast cancer metastasis (fig 1).
Further investigation including mammography, ultrasound, and magnetic resonance imaging of both breasts showed a $15 \mathrm{~mm}$ suspicious mass in the left breast. A lumpectomy and lymph node dissection was carried out. The lesion was diagnosed as a ductal adenocarcinoma and all dissected lymph nodes $(\mathrm{n}=28)$ were normal. After tumour resection, fever, and all other symptoms of AOSD, including serological markers of inflammation such as ESR, CRP, and ferritin, returned to normal without further symptomatic treatment. The patient is currently receiving adjuvant chemotherapy.

\section{DISCUSSION}

AOSD is an inflammatory disorder of unknown aetiology characterised by fever, arthritis, and skin rashes. ${ }^{1-4}$

Symptoms of AOSD are known to occur in patients with haematological malignancies. However, they have also rarely been described as the first symptoms in patients with breast cancer, ${ }^{5-7}$ although fever as a paraneoplastic symptom is generally uncommon in such patients. ${ }^{8}$ Interestingly, published reports describe patients with similar features: all had metastatic cancer affecting lymph nodes with a relatively small tumour mass and in all patients the AOSD-like symptoms resolved completely after successful tumour treatment. Thus metastatic breast cancer, as well as lymphoma and leukaemia may mimic AOSD. The unusual presentation (AOSD) of an all too common disease (metastatic breast cancer) should remind us that symptoms of rheumatic diseases can sometimes be clues to occult malignancies ${ }^{9}$ and emphasises the importance of a thorough search for underlying occult neoplastic disease.

\section{Authors' affiliations}

M von Lilienfeld-Toal, F L Dumoulin, Department of Medicine I,

University of Bonn, D-53127 Bonn, Germany

S Merkelbach-Bruse, Institute of Pathology, University of Bonn, D-53127 Bonn, Germany

Conflict of interest: No conflict of interest has been declared by the authors. The patient's written consent was obtained according to the Declaration of Helsinki (BMJ 1996;31:1448-9).
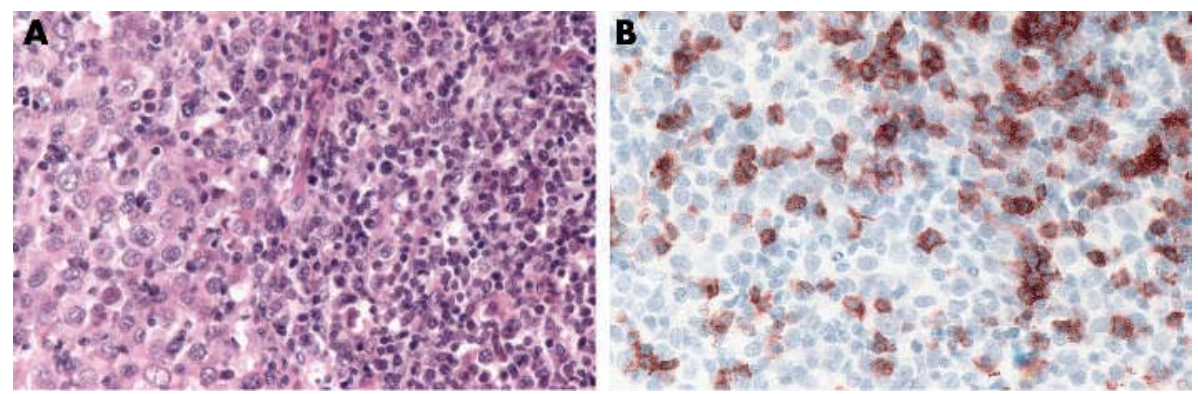

Figure 1 Histopathological finding of the axillary lymph node biopsy (magnification $\times 250$ ). Note the metastatic infiltration (haematoxylin and eosin stain (A)) and the dense lymphocytic infiltrate consisting of CD8 positive T lymphocytes (immunoperoxidase stain (B)). Polymerase chain reaction analysis showed a polyclonal pattern of $\mathrm{V}$ gamma rearrangement (data not shown). 
Correspondence to: Dr F L Dumoulin; dumoulin@uni-bonn.de

Accepted 17 October 2003

\section{REFERENCES}

1 Yamaguchi M, Ohta A, Tsunematsu T, Kasukawa R, Mizushima Y, Kashiwagi $\mathrm{H}$, et al. Preliminary criteria for classification of adult Still's disease. $J$ Rheumatol 1992; 19:424-30.

2 Reginato AJ, Schumacher Jr HR, Baker DG, O'Connor CR, Ferreiros J. Adult onset Still's disease: experience in 23 patients and literature review with emphasis on organ failure. Semin Arthritis Rheum 1987:17:39-57.

3 Kahn MF. Maladie de Still de I'adulte. In: Kahn MF, Peltier A, eds. Les maladies systemiques. Paris: Flammarion, 1991.
4 Fautrel B, Zing E, Golmard JL, Le Moel G, Bissery A, Rioux C, et al. Proposal for a new set of classification criteria for adult-onset still disease. Medicine (Baltimore) 2002;81:194-200.

5 Rogues AM, Vidal E, Boudinet F, Loustaud V, Arnaud M, Liozon F. Breast cancer with systemic manifestations mimicking Still's disease. J Rheumatol 1993:20:1786-7.

6 Drenth JP, de Kleijn EH, de Mulder PH, van der Meer JW. Metastatic breast cancer presenting as fever, rash, and arthritis. Cancer 1995;75:1608-11.

7 Neishi J, Tsukada Y, Maehara T, Ueki K, Maezawa A, Noiima Y. Adult Still's disease as a paraneoplastic manifestation of breast cancer. Scand J Rheumatol 2000;29:328-30.

8 Chawla SP, Buzdar AU, Hortobagyi GN, Blumenschein GR. Tumor-associated fever in breast cancer. Cancer 1984:53:1596-9.

9 Naschitz JE, Rosner I, Rozenbaum M, Zuckerman E, Yeshurun D. Rheumatic syndromes: clues to occult neoplasia. Semin Arthritis Rheum 1999;29:43-55.

\section{Combined therapy for pyoderma gangrenosum}

\section{A P Rozin, A Balbir-Gurman, L Gilead, D Slodownik}

W report a case of successful combined therapy for rapidly progressive pyoderma gangrenosum (PG). A 78 year old woman was admitted to the department of rheumatology with large right leg skin ulcers affecting the anterior and mediolateral lower shin region (fig 1A). The lesions had developed from small pustules to a focus of large painful skin damage during the past month. Her past history was free of any skin disease. Arterial hypertension, depression, and osteoporosis were controlled with permanent treatment. Her laboratory findings were unremarkable, including negative hepatitis B surface antigen and hepatitis $\mathrm{C}$ virus and normal liver function.

A marginal biopsy was performed, which highlighted a massive neutrophil infiltrate invading subcutaneous fat with necrotic debris associated with PG, with no evidence of vasculitis, malignancy, or infection. The patient had had seropositive rheumatoid arthritis for 32 years and her joint disease was controlled with long term treatment with azathioprine $150 \mathrm{mg} /$ day. Despite the large rapidly progressive skin lesion and threat of leg amputation we decided to stop azathioprine and to begin combined therapy. This treatment included intravenous monthly cyclophosphamide pulse therapy $1000 \mathrm{mg}(20 \mathrm{mg} / \mathrm{kg})$, oral cyclosporin A $100 \mathrm{mg} /$ day $(2 \mathrm{mg} / \mathrm{kg})$, a moderate dose of prednisone $30 \mathrm{mg} /$ day $(0.6 \mathrm{mg} / \mathrm{kg})$ with tapering to $20 \mathrm{mg} /$ day after 2 months, and a local treatment. To achieve a clean wound, she underwent one session of maggot debridement treatment (MDT). After confirming a normal ankle brachial index by duplex we started to apply two layer pressure dressings with occasional granulation tissue promoters. After 3 months of the treatment the wound healed completely (fig 1B). Three additional monthly pulses of cyclophosphamide were given. The patient's present treatment comprises cyclosporin A $2 \mathrm{mg} / \mathrm{kg}$ and prednisone $10 \mathrm{mg} /$ day. She is well, has normal daily living, and no active arthritis.

\section{DISCUSSION}

PG is a non-infectious neutrophilic dermatosis that usually starts with sterile pustules, which rapidly progress to painful ulcer with undermined violaceous borders. In $17-74 \%$ cases, PG is associated with an underlying disease, most commonly inflammatory bowel disease, rheumatological or haematological disease, or malignancy. Diagnosis of PG is based on a history of an underlying disease, typical clinical presentation,

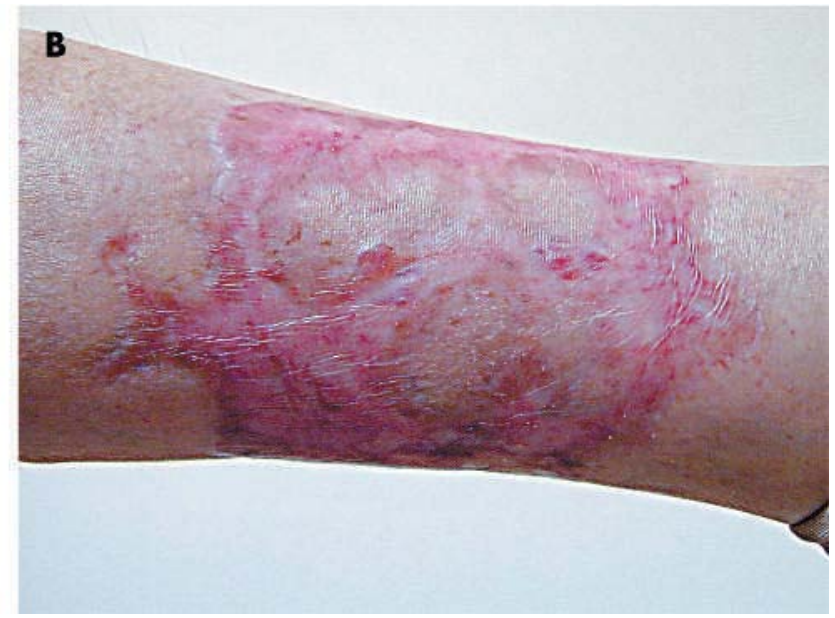

Figure 1 (A) Large ulcers of pyoderma gangrenosum with an irregular, well defined, undermined, partially raised violaceous border on admission. (B) Complete healing of the wound after combined prednisone-cyclosporin A-pulse cyclophosphamide therapy and local maggot debridement 3 months later. 
and histopathology, and exclusion of other diseases that would lead to a similar appearance. Despite recent advances in treatment, the prognosis of PG remains unpredictable. ${ }^{1}$ The optimal treatment of PG includes a combination of local wound care and systemic treatment. Often, it is difficult to control aggressive cases, necessitating administration of a combination of systemic treatments. ${ }^{2}$ We followed this way and administered first line treatment of high dose corticosteroids and cyclosporin $\mathrm{A}^{3}$ along with monthly pulses of cyclophosphamide. ${ }^{45}$ MDT was first introduced in America in 1931. Sterile maggots of the green bottle fly Lucilia (Phacnicia) scricata are used for MDT. Up to 1000 maggots are introduced into the wound and left for 1-3 days. One of the major advantages of MDT is that the maggots separate the necrotic tissue from the living tissue. In $80-95 \%$ of cases a complete or significant debridement of the wound is achieved. An immediate amputation can be prevented as a result of MDT. ${ }^{6}$ In another study 21 ambulatory patients with nonhealing wounds were treated with $\mathrm{MDT}^{7}$ Of the eight patients who were advised to undergo amputation or major surgical debridement, only three required surgical resection (amputation) after MDT. Eleven healed without any additional surgical procedures. ${ }^{7}$ It is a simple, efficient, well tolerated, and cost effective tool for the treatment of wounds and ulcers which do not response to conventional treatment. ${ }^{6}$ We used it as first line treatment together with systemic treatment and achieved a rapid and complete effect.
Authors' affiliations

A P Rozin, A Balbir-Gurman, B Shine Department of Rheumatology, Rambam Medical Centre and B Rappaport Faculty of Medicine, IsraelTechnion Institute of Technology, Haifa, Israel

L Gilead, D Slodownik, Department of Dermatology, Hadassah Medical Centre, Jerusalem, Israel

Correspondence to: Dr A P Rozin, Bat Galim, Rambam Medical Centre, PO Box 9602 Haifa, Israel, 31096; a_rozin@rambam.health.gov.il

Accepted 3 November 2003

\section{REFERENCES}

1 Wollina U. Clinical management of pyoderma gangrenosum. Am J Clin Dermatol 2002;3:149-58.

2 Gettler S, Rothe M, Grin C, Grant-Kels J. Optimal treatment of pyoderma gangrenosum. Am J Clin Dermatol 2003;4:597-608.

3 Hugghes JR, Smith E, Higgins EM, Berry H, du Vivier AW. Pyoderma gangrenosum in a patient with rheumatoid arthritis responding to treatment with cyclosporin A. Br J Rheumatol 1994;33:680-1.

4 Zonana-Nacach A, Jimenez-Balderas FJ, Martinez-Osuna P, Mintz C. Intravenous cyclophosphamide pulses in the treatment of pyoderma gangrenosum associated with rheumatoid arthritis: report of 2 cases and review of the literature. J Rheumatol 1994;21:1352-6.

5 Reynoso-von Drateln C, Perla-Navarro AV, Gamez-Nava Jl, GonzalesLopez L, Galvan-Villegas F, Ramos-Remus C. Intravenous cyclophosphamide pulses in pyoderma gangrenosum: an open trial. J Rheumatol 1997;24:689-93.

6 Mumcuoglu KY. Clinical applications for maggots in wound care. Am J Clin Dermatol $2001 ; 2: 219-27$.

7 Sherman RA, Sherman J, Gilead L, Lipo M, Momcuoglu KY. Maggot debridement therapy in outpatients. Arch Phys Med Rehabil $2001 ; 82: 1226-9$.

\section{Benefit of immunosuppression for severe Takayasu's arteritis and coincident primary biliary cirrhosis}

\section{E Feist, K G A Hermann, S Filimonow, R I Rückert, T Dörner, F Hiepe}

$\mathrm{T}$ akayasu's arteritis and primary biliary cirrhosis (PBC) are two unrelated autoimmune diseases without a so far reported coincidence, probably because they occur at different ages. ${ }^{12}$ As a systemic vasculitis, Takayasu's arteritis affects predominantly the aorta and its branches in female patients before the age of 40 years. The clinical manifestations are variable and severe anatomical lesions can lead to life threatening ischaemia. We report an unusual case, where, after the initial diagnosis of a coincident severe Takayasu's arteritis with $\mathrm{PBC}$, subsequent immunosuppressive treatment led to a striking clinical improvement of vasculitic symptoms in an elderly woman.

\section{CASE REPORT}

A 70 year old woman was referred to our hospital with generalised weakness and disseminated painful cutaneous, erythematous nodules on the extensor sites of both lower legs. A rheumatic disorder had been suspected since 1960 because of remittent nausea, attacks of fulminant headaches, and an erythema nodosum. Clinical examination showed a diminished bilateral radial and an absent carotid pulse as well as hypotensive blood pressure on both arms (85/60 and $90 / 60 \mathrm{~mm} \mathrm{Hg}$ ). No focal neurological and no pathological musculoskeletal findings were present.

In laboratory analysis, a raised erythrocyte sedimentation rate of $52 \mathrm{~mm}$ within the first hour as well as a $C$ reactive protein of $14 \mathrm{mg} / \mathrm{l}$ (normal $<8$ ) were detected. Liver enzymes and measures of cholestasis were moderately raised.
Antinuclear antibodies were positive at a titre of $1 / 1280$, with a dense granular nucleoplasmic pattern and cytoplasmic staining suggesting antimitochondrial antibodies (AMA). AMA were confirmed in immunofluorescence on rat kidney cells at a positive titre of $1 / 32$, and in AMA-M2 enzyme linked immunosorbent assay (ELISA; $>500 \mathrm{U} / \mathrm{ml}$, normal $<10$ ).

In Doppler sonography, occlusion of both common carotid arteries (CCA) and of both internal carotid arteries (ICA) as well as of the left subclavian artery was detected. The filiforme external carotid arteries showed an antegrade flow on the right and a retrograde flow on the left side. Along the right subclavian artery, examination showed a post-stenotic signal. Perfusion of the brain was ensured by two hypertrophic vertebral arteries with a suspected stenosis on the right side. These severe anatomical changes were confirmed by digital subtraction angiography (fig 1A). Ultrasound examination of the abdomen showed no signs of involvement of abdominal vessels, but a chronic alteration of liver tissue.

Despite the age of our patient, Takayasu's arteritis was diagnosed with the assumption of a disease duration of four decades. Moreover, the remittent attacks of headaches and nausea, the skin involvement, and raised inflammatory parameters were consistent with an active vasculitis. A coincident $\mathrm{PBC}$ was supported by high positive AMA, raised measures of cholestasis, and morphological liver changes. ${ }^{3}$ Therefore, a therapeutic approach with corticosteroids (initially $50 \mathrm{mg}$ a day) in combination with a cyclophosphamide bolus (700 mg) was justified. Immediately, a clear 

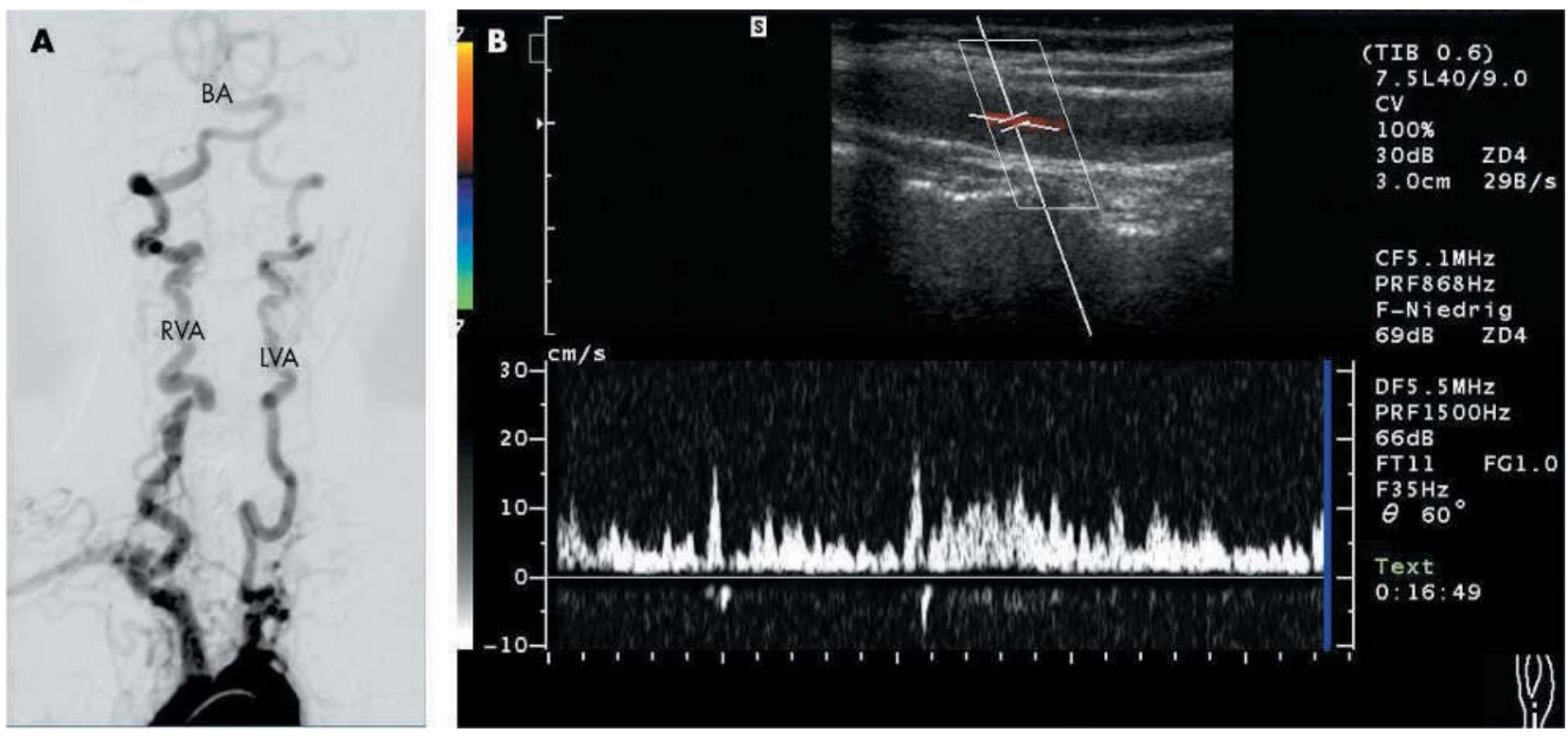

Figure 1 (A) Conventional digital subtraction angiography shows occlusions of both CCA and ICA, an occlusion of the left subclavian artery, and luminal narrowing of the right subclavian artery. Both vertebral arteries are elongated and hypertrophied, a luminal narrowing is present on the left side in contrast with sonography. (B) Follow up colour coded Doppler sonography showed a reduced antegrade flow in the still extremely wall thickened right CCA.

improvement of the overall condition and the skin lesions was accompanied by a normalisation of the inflammatory parameters. However, to our surprise, the headaches and the nausea improved also. Two months after the start of treatment, a minimal perfusion of the right CCA and right ICA was noted in magnetic resonance angiography. The treatment was continued with methotrexate in combination with low dose steroids. Additionally, low dose aspirin, a well tolerated calcium antagonist, and ursodesoxycholic acid completed the drug treatment. One year later, a follow up colour coded Doppler sonography showed reduced antegrade flow in the right CCA $(20 \mathrm{~cm} / \mathrm{s})$ (fig $1 \mathrm{~B})$ as well as in the right ICA $(40 \mathrm{~cm} / \mathrm{s})$, and retrograde flow in the right external carotid artery $(70 \mathrm{~cm} / \mathrm{s})$. Over a follow up period of 3 years, the clinical, vascular, and laboratory findings remained stable.

\section{DISCUSSION}

The supra-aortic vessel occlusions in this case were consistent with a giant cell vasculitis. After consideration of the patient's history, Takayasu's arteritis was diagnosed, but it was not possible to exclude Horton's disease, considering the clinical manifestations. The improvement in headaches, especially, could argue for giant cell arteritis, but conversely, the anatomical changes were more typical of Takayasu's arteritis.

Regression of vessel occlusions remains rare in Takayasu's arteritis as well as in giant cell arteritis. On the other hand, it is not always possible to exclude a persistent active giant cell vasculitis of the aortic wall or even of its branches using conventional techniques. The presented case reflects this situation by an unexpected improvement of cerebral perfusion and eventually of the neurological symptoms after immunosuppressive treatment. However, despite the encouraging outcome in our case, adequate treatment in Takayasu's vasculitis remains a problem. Remarkably, immunosuppressive treatment can be effective even in longlasting and occlusive situations of giant cell vasculitis. A coincidence of different systemic forms of vasculitis with PBC has been reported previously and, therefore, in suspicious cases an autoimmune liver disease should be excluded. ${ }^{4-7}$

\section{Authors' affiliations}

E Feist, T Dörner, F Hiepe, Department of Rheumatology and Clinical Immunology, Charité University Hospital, Humboldt University of Berlin, Schumannstr 20/21, 10117 Berlin, Germany

R I Rückert, Clinic of General, Visceral, Vascular, and Thoracic Surgery, Charité University Hospital, Humboldt University of Berlin, Schumannstr 20/21, 10117 Berlin, Germany

K G A Hermann, S Filimonow, Department of Radiology, Charité

University Hospital, Humboldt University of Berlin, Schumannstr 20/21, 10117 Berlin, Germany

Correspondence to: Dr E Feist, eugen.feist@charite.de

Accepted 6 November 2003

\section{REFERENCES}

1 Johnston SL, Lock RJ, Gompels MM. Takayasu arteritis: a review. J Clin Pathol 2002;55:481-6.

2 Burt AD. Primary biliary cirrhosis and other ductopenic diseases. Clin Liver Dis 2002;6:363-80.

3 Neuberger J, Bradwell AR. Anti-mitochondrial antibodies in primary biliary cirrhosis. J Hepatol 2002:37:712-16.

4 Gagnerie F, Taillan B, Euller-Ziegler L, Ziegler G. Primary biliary cirrhosis, temporal arteritis (giant cell arteritis) and polymyalgia rheumatica in a single patient. Scand J Rheumatol 1988;17:231-2.

5 Conn DL, Dickson ER, Carpenter HA. The association of Churg-Strauss vasculitis with temporal artery involvement, primary biliary cirrhosis, and polychondritis in a single patient. J Rheumatol 1982;9:744-8.

6 Terkeltaub R, Esdaile JM, Bruneau C, Danoff D, Watters AK. Vasculitis as a presenting manifestation of primary biliary cirrhosis: a case report. Clin Exp Rheumatol 1984:2:67-73.

7 Harada N, Dohmen K, Itoh H, Ohshima T, Yamamoto H, Nagano M, et al. Sibling cases of primary biliary cirrhosis associated with polymyositis, vasculitis and Hashimoto's thyroiditis. Intern Med 1992;31:289-93. 


\section{Effect of etanercept on matrix metalloproteinases and angiogenic vascular endothelial growth factor: a time kinetic study}

\section{A Aggarwal, S Panda, R Misra}

C hronic synovitis in rheumatoid arthritis results in the formation of pannus that invades the joint cartilage and the underlying bone. Matrix metalloproteinases (MMPs) can degrade cartilage, bone, and connective tissue matrix. ${ }^{1}$ Of these matrix degrading enzymes, MMP-1 is the most important and is present in the synovial lining of patients with rheumatoid arthritis (RA). ${ }^{2}$ In synovial tissue, the level of tissue inhibitor of MMP (TIMP) is reduced, tilting the balance towards tissue destruction. The effect of soluble tumour necrosis factor receptor (sTNFr) on these mediators is not known, because the only study available had pooled data of patients treated with sTNFr alone and in combination with methotrexate. ${ }^{3}$

Angiogenesis is central to the maintenance of pannus and is controlled by many factors. Identification of vascular endothelial growth factor (VEGF) as the major angiogenic
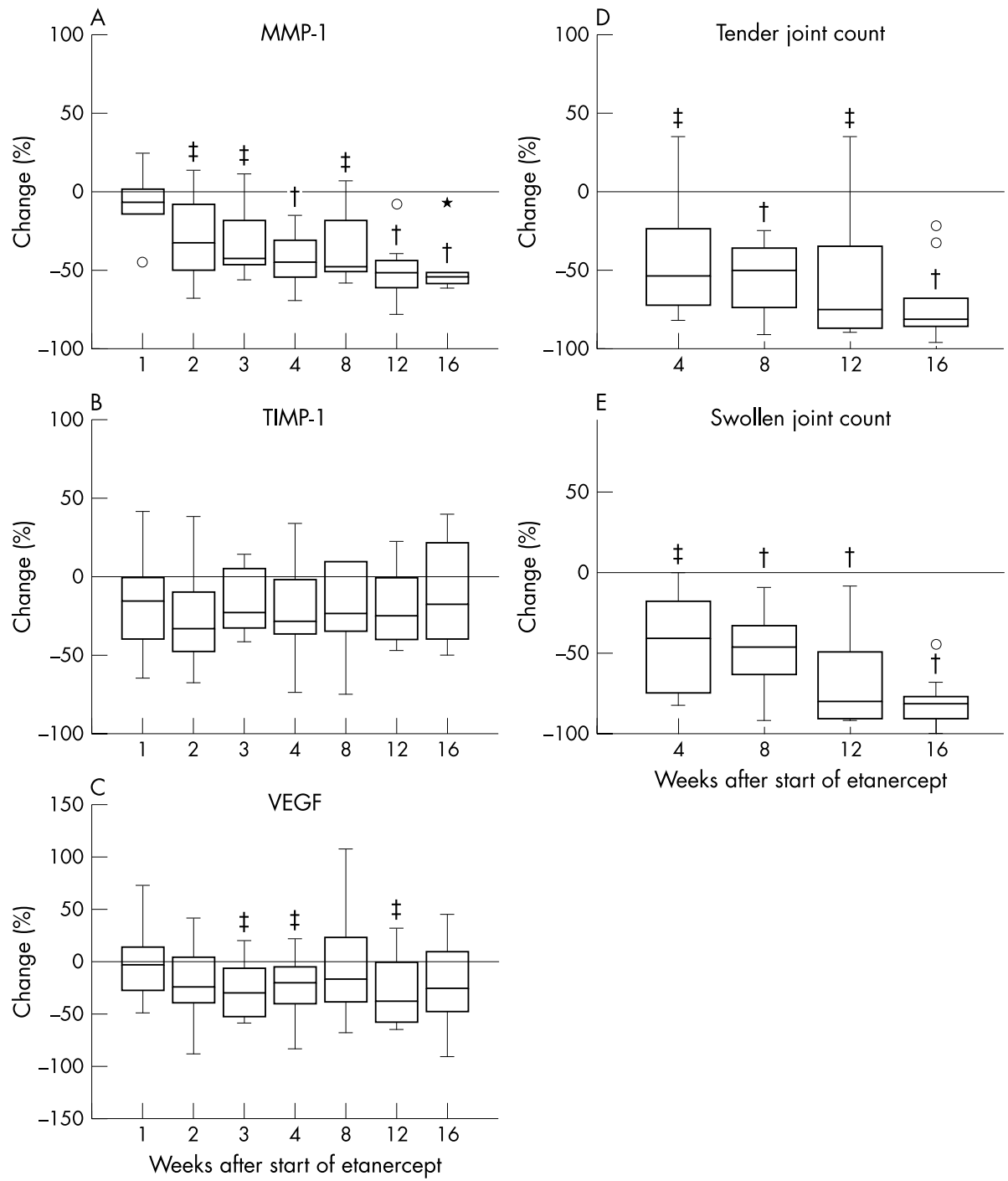

Weeks after start of etanercept

Figure 1 Box plot showing the percentage change at different times in patients treated with etanercept as compared with the baseline value in each patient (A) MMP-1; (B) TIMP-1; (C) VEGF; (D) 28 tender joint count; (E) 28 swollen joint count. o depicts outliers and * depicts extreme values. $\dagger \mathrm{p}<0.05, \pm \mathrm{p}<0.005$. For values with $\mathrm{t}_{\mathrm{p} \text { corr }}$ was not significant after Bonferroni's correction. 
factor, demonstration of its presence in the synovial tissue of patients with RA, ${ }^{4}$ and suppression of collagen induced arthritis by its inhibitor suggest that it may have a role in the angiogenesis of RA. ${ }^{5}$ TNF up regulates the production of VEGF. ${ }^{6}$ No data are available on the effect of sTNFr on VEGF. Thus we studied the effect of sTNFr monotherapy on VEGF and MMPs in patients with RA.

Ten patients with RA (all women, nine seropositive, mean age 35.2 years, mean duration of disease 6.2 years $)^{7}$ were studied. They received $25 \mathrm{mg}$ of sTNFr (etanercept) twice weekly subcutaneously. No other disease modifying antirheumatic drugs were given. Plasma samples were collected at baseline and then weekly for the first 1 month and monthly thereafter for the next 3 months. Clinical assessment included 28 swollen joint count, 28 tender joint count, duration of early morning stiffness, physician's and patient's global assessment, and Health Assessment Questionnaire. VEGF, MMP-1, and TIMP were measured by sandwich enzyme linked immunosorbent assay (ELISA; R\&D, Minneapolis, USA). C reactive protein was measured by turbidimetery. Non-parametric tests were used for correlation and intergroup comparison.

There was a good correlation between the levels of $\mathrm{C}$ reactive protein and those of VEGF $(p<0.001)$ and MMP $(p<0.002)$. After treatment the levels of MMP fell significantly (fig lA) as compared with baseline values as early as 2 weeks after the start of treatment. The levels of TIMP-1 however remained unchanged (fig IB). VEGF levels also fell but to a lesser degree (fig IC). These effects paralleled changes in clinical parameters like tender joint count or swollen joint count (figs $1 \mathrm{D}$ and E).

MMPs cause tissue destruction because of their proteolytic abilities. Our data of more than 50\% decrease in MMP-1 within 2 weeks of the start of treatment suggest that TNF blockade down regulates production of MMPs. Recently, sTNFr treatment has been shown to reduce MMP expression in the synovial membrane. ${ }^{3}$ Anti-TNF antibody has also been shown to have similar effect on MMPs. ${ }^{8}$ An ideal treatment will be one which increases levels of TIMP and reduces levels of MMP. Unfortunately, most data, ${ }^{3}$ including ours, show that TIMP levels are either not affected or are reduced to a smaller degree than MMPs with TNF blockade. Even this change is likely to tilt the balance in favour of TIMP and thus prevent action of MMPs and tissue damage.

As far as we know, our study is the first to demonstrate the effect of sTNFr on plasma VEGF in patients with RA, even though the effect was mild. Reduction in serum VEGF levels was also reported with the use of anti-TNF antibody. ${ }^{6}$ However, serum VEGF levels may be confounded by VEGF released by platelets, which may increase with the thrombocytosis of inflammation. Hence we measured plasma VEGF levels.

Thus sTNFr has significant and early effect on mediators of tissue damage.

\section{ACKNOWLEDGEMENTS}

This work was supported by a research grant to AA from the author's institution. Etanercept was supplied by Wyeth Lederle Ltd as part of a multi-institutional study.

\section{Authors' affiliations}

A Aggarwal, S Panda, R Misra, Department of Immunology, Sanjay Gandhi Postgraduate Institute of Medical Sciences, Lucknow, India

Correspondence to: Dr A Aggarwal, amita@sgpgi.ac.in

Accepted 17 July 2003

\section{REFERENCES}

1 Ladner UM, Gay RE, Gay S. Signalling and effector pathways. Curr Opin Rheumatol 1999;11:194-201.

2 Tetlow LC, Woolley DE. Comparative immunolocalization studies of collagenase 1 and collagenase 3 production in the rheumatoid lesion and by human chondrocytes and synoviocytes in vitro. Br J Rheumatol 1998:37:64-70.

3 Catrina Al, Lampa J, Ernestam S, af Klint E, Bratt J, Klareskog L, et al. Antitumor necrosis factor (TNF)- $\alpha$ treatment (etanercept) down regulates serum matrix metalloproteinases (MMP)-3 and MMP-1 in rheumatoid arthritis. Rheumatology (Oxford) 2002;41:484-9.

4 Koch AE. Angiogenesis-implications for rheumatoid arthritis. Arthritis Rheum 1998;41:951-62.

5 Bandt M, Grossin M, Weber AJ, Chopin M, Elbim C, Pla M, et al. Suppression of arthritis and protection from bone destruction by treatment with TNP-470/ AGM-1470 in a transgenic mouse model of rheumatoid arthritis. Arthritis Rheum 2000;42:2056-63

6 Paleolog EM, Young S, Stark AC McCloskey Feldmann M, Maini RN. Modulation of angiogenic vascular endothelial growth factor by tumor necrosis factor-alpha and IL-1 in rheumatoid arthritis. Arthritis Rheum 1998;41:1258-65.

7 Arnett FC, Edworthy SM, Bloch DA, McShane DJ, Fries JF, Cooper NS, et al. The American Rheumatism Association 1987 revised criteria for the classification of rheumatoid arthritis. Arthritis Rheum 1988;31:315-24.

8 Brennan FM, Browne KA, Green PA, Jaspar J-M, Maini RN, Feldmann M. Reduction of serum matrix metalloproteinase 1 and matrix metalloproteinase 3 in rheumatoid arthritis patients following anti-TNF (cA2) therapy. Br J Rheumatol 1997;36:643-50.

\title{
Cytokine profile of bronchoalveolar lavage in systemic sclerosis with interstitial lung disease: comparison with usual interstitial pneumonia
}

\author{
F Meloni, R Caporali, A Marone Bianco, E Paschetto, M Morosini, A M Fietta, F Bobbio-Pallavicini, \\ E Pozzi, C Montecucco
}

Ann Rheum Dis 2004;63:892-894. doi: 10.1136/ard.2003.014019

nterstitial lung disease (ILD), which often develops in systemic sclerosis (SSc), is associated with a better prognosis than idiopathic usual interstitial pneumonia
(UIP) because only a limited number of patients with SSc progress to end stage fibrosis. ${ }^{12}$ Mechanisms driving the fibrotic evolution of ILD are still poorly understood, 
Table 1 IL8, IL10, and IL18 BALF levels in patients with systemic sclerosis associated interstitial lung disease (SSc-ILD) or usual interstitial pneumonia (UIP), and in control subjects

\begin{tabular}{llll}
\hline & SSc-ILD & UIP & Controls \\
\hline IL8 $(\mathrm{pg} / \mathrm{ml})$ & $24.5(6.5-46.6)^{*}$ & $34.95(19.4-52.2)^{*}$ & $13.7(8.8-16.5)$ \\
IL10 $(\mathrm{pg} / \mathrm{ml})$ & $1.5(0.0-6.25)^{*}$ & $0.50(0.3-0.5)$ & $0.0(0.0-0.0)$ \\
IL18 $(\mathrm{pg} / \mathrm{ml})$ & $100.7(42.1-153.8)$ & $56.4(19.9-114.4)$ & $47.6(24.5-214.3)$ \\
\hline
\end{tabular}

*Significant difference with respect to controls (Mann-Whitney $U$ test, $p \leqslant 0.05$ ).

Data are expressed as pg of cytokine per $\mathrm{ml}$ of recovered BAL fluid. Median values and 25th-75th centile intervals are shown.

but, recently, on the basis of animal models, a pathogenetic role has been ascribed to an imbalance in the local Thl/Th2 response, with an expansion of the Th2 profile. $^{3}$

\section{METHODS AND RESULTS}

We studied the cytokine profile of bronchoalveolar lavage fluid (BALF) of 28 patients with SSc-ILD (6 men, 22 women; mean (SD) age 50.3 (8.9) years). All patients with SSc satisfied the preliminary American College of Rheumatology (ACR) criteria for classification of the disease, ${ }^{4}$ and respiratory disease was defined on the basis of functional tests and high resolution computed tomography findings as at least grade 1 severity, according to the disease severity scale for SSc. ${ }^{5}$ Seven $(25 \%)$ patients with SSc had limited and $21(75 \%)$ diffuse disease. All were positive for antinuclear antibodies; 18 for anti-topoisomerase I, and one for anti-RNA
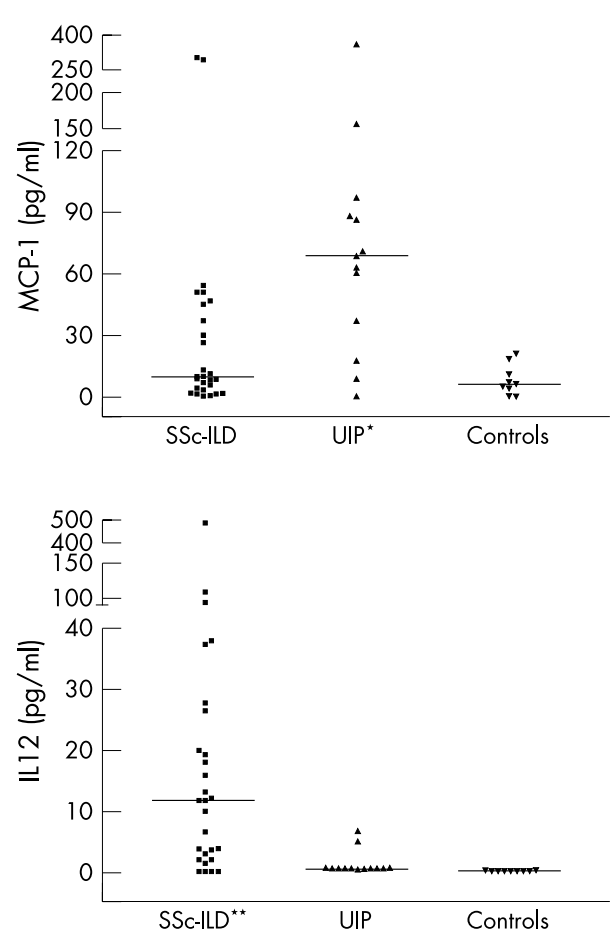

Figure 1 MCP-1 and IL12 BALF levels in patients with systemic sclerosis associated interstitial lung disease (SSc-ILD) or patients with usual interstitial pneumonia (UIP), and in control subjects. Data are expressed as pg of cytokine per $\mathrm{ml}$ of recovered BALF. Median values and 25th75th centile intervals are shown. *Significant difference with respect to controls (Mann-Whitney U test, $p \leqslant 0.05$ ); ${ }^{* *}$ significant difference with respect to both UIP and controls (Mann-Whitney U test, $p \leqslant 0.05)$. polymerase I and III. Results were compared with those obtained in 13 patients with UIP ( 10 men, three women; mean (SD) age 56 (16.8) years; all newly diagnosed, previously untreated patients); and nine normal controls (seven men, two women, mean (SD) age 42.7 (12.1) years).

The following cytokines were assessed on concentrated (by ultrafiltration) BALF: two proinflammatory chemokines interleukin (IL) 8 and monocyte chemotactic protein-1 (MCP-1), two Thl related factors IL12 and IL18, and one anti-inflammatory Th2 related cytokine IL10. Data, expressed as medians (25th-75th centile) were analysed with the Mann-Whitney U test (Kolmogornov-Smirnov test, $\mathrm{p} \leqslant 0.05)$.

Table 1 shows that BALF levels of IL8 were increased in patients with SSc-ILD and UIP in comparison with controls $(p=0.05$ and $p=0.004)$. In addition, a trend towards an increase of IL8 levels in UIP compared with SSc-ILD was found $(p=0.07)$. Levels of MCP-1 were markedly and significantly raised only in patients with UIP in comparison with both SSc-ILD and controls (fig 1). For the Thl related cytokines, IL18 values did not differ significantly among the groups (table 1), but higher levels were detected in control BALFs. These findings suggest a relatively high constitutional release of IL18 in physiological conditions. On the contrary, IL12 was almost undetectable in BALF from controls, but it was markedly increased in patients with SSc-ILD $(p=0.0008)$ (fig 1). Moreover, IL10 levels were higher in SSc-ILD than in controls $(p=0.02$; table 1$)$. Finally, no differences in the BALF cytokine levels were seen among patients with SSc-ILD according to their clinical or serological subset $(\mathrm{p}>0.05)$.

\section{DISCUSSION}

Data presented here suggest the presence of a different BALF cytokine profile in SSc-ILD than in UIP. In particular, we found that patients with SSc-ILD had increased levels of IL12, a cytokine shown to attenuate bleomycin induced lung fibrosis in rats. ${ }^{67}$ This might suggest a protective activity of IL12 with respect to the fibrotic evolution in SSc-ILD. In addition, we found that MCP-1 was significantly raised in UIP BALF but only slightly increased in SSc-ILD. Moreover, MCP-1 BALF levels correlated significantly $(p=0.004)$ with BALF eosinophil counts that are known to be a prognostic factor in SSc-ILD. In fact, MCP-1 has been shown to provoke chronic fibrogenic lung inflammation in animal models of lung fibrosis induced by bleomycin, radiation, or FITC. ${ }^{8-10}$ Finally, levels of the anti-inflammatory IL10 were higher in SSc-ILD than in controls.

In conclusion, the BALF cytokine profile in SSc-ILD seems to express a more favourable balance between fibrotic (MCP-1) and anti-fibrotic or anti-inflammatory factors (IL12 and IL10) than that in UIP, and this may account for the better prognosis of interstitial damage associated with SSc. Further longitudinal studies are necessary to confirm 
whether a different cytokine phenotype might be considered predictive of clinical outcome.

\section{Authors' affiliations \\ F Meloni, A Marone Bianco, E Paschetto, M Morosini, A M Fietta, \\ E Pozzi, Department of Haematological, Pneumological and Cardiovascular Sciences, Section of Pneumology, University of Pavia and IRCCS Policlinico San Matteo, Pavia, Italy \\ R Caporali, F Bobbio-Pallavicini, C Montecucco, Department of Internal Medicine and Medical Therapy, Section of Rheumatology, University of Pavia and IRCCS Policlinico San Matteo, Pavia, Italy \\ Correspondence to: Dr F Meloni, Dipartimento di Scienze Ematologiche, Pneumologiche e Cardiovascolari Mediche e Chirurgiche, Sezione di Pneumologia, Università di Pavia, IRCCS Policlinico San Matteo, Via Taramelli 5, 27100 Pavia, Italy; federica_meloni@ libero.it \\ Accepted 26 July 2003 \\ REFERENCES \\ 1 Bouros D, Wells AU, Nicholson AG, Colby TV, Polychronopoulos V, Pantelidis $\mathrm{P}$, et al. Histopathologic subsets of fibrosing alveolitis in patients with systemic sclerosis and their relationship to outcome. Am J Respir Crit Care Med 2002;165: 1581-6.}

2 Cheema GS, Quismorio FP Jr. Interstitial lung disease in systemic sclerosis. Curr Opin Pulm Med 2001; 7:283-90

3 Lukacs NW, Hogaboam C, Chensue SW, Blease K, Kunkel SL. Type 1/type 2 cytokine paradigm and the progression of pulmonary fibrosis. Chest 2001;120:5-8S

4 Anonymous. Preliminary criteria for the classification of systemic sclerosis (scleroderma). Subcommittee for Scleroderma Criteria of the American Rheumatism Association Diagnostics and Therapeutics Criteria Committee. Preliminary criteria for the classification of systemic sclerosis (scleroderma). Arthritis Rheum 1990;23 581-90.

5 Medsger TA, Silman AJ, Steen VD, Black CM, Akesson A, Bacon PA, et al. A disease severity scale for systemic sclerosis: development and testing. J Rheumatol 1999;26:2159-67.

6 Keane MP, Belperio JA, Burdick MD, Strieter RM. IL-12 attenuates bleomycininduced pulmonary fibrosis. Am J Physiol Lung Cell Mol Physiol 2001;281:L92-7.

7 Sakamoto H, Zhao LH, Jain F, Kradin R. IL12p4O(-/-) mice treated with intratracheal bleomycin exhibit decreased pulmonary inflammation and increased fibrosis. Exp Mol Pathol 2002;72:1-9.

8 Anonymous. Technical recommendations and guidelines for bronchoalveolar lavage (BAL). Report of the European Society of Pneumology Task Group. Eur Respir J 1989;2:561-85.

9 Johnston CJ, Williams JP, Okunieff P, Finkelstein JN. Radiation-induced pulmonary fibrosis: examination of chemokine and chemokine receptor families. Radiat Res 2002;157:256-65.

10 Zhang Y, McCormick LL, Desai SR, Wu C, Gilliam AC. Murine sclerodermatous graft-versus-host disease, a model for human scleroderma: cutaneous cyłokines, chemokines, and immune cell activation. J Immunol 2002; 168:3088-98.

\section{Gout in liver transplant patients receiving tacrolimus}

\section{J C Gerster, M Dudler, N Halkic, M Gillet}

$\mathrm{H}$ yperuricaemia and gout have been reported in organ transplant patients treated with cyclosporin, an immunosuppressant inhibiting calcineurin. ${ }^{2}$ Tacrolimus, another calcineurin inhibitor, is nowadays widely used in place of cyclosporin. Hyperuricaemia has been seen in patients receiving tacrolimus ${ }^{3}$ but, to our knowledge, only rare cases of gout have been mentioned so far. ${ }^{4}$

Since 1998, 31 patients ( 22 men, 9 women; current mean age 53 years (range 24-67)) have regularly received tacrolimus for immunosuppression after liver transplantation in the surgical department of Lausanne University Hospital. The mean duration of follow up with tacrolimus treatment was 27.8 months (range 7-57).

In two cases the first manifestations of gout appeared after liver transplantation when these two patients were receiving tacrolimus for immunosuppression.

\section{CASE REPORTS}

\section{Patient 1}

A 31 year old man received a liver transplant in November 1998. He was treated with tacrolimus at a daily dose of $6 \mathrm{mg}$, as well as prednisone. He also was receiving treatment with furosemide. In July 1999 he presented episodes of acute arthritis of the right wrist and both elbows. The serum uric acid level was $421 \mu \mathrm{mol} / \mathrm{l}$ and creatinine $105 \mu \mathrm{mol} / \mathrm{l}$. Gout was not diagnosed until March 2000, when he started to have severe compression of the right median nerve, owing to a voluminous mass located in the anterolateral part of the wrist (fig 1A), which was suspected to be tumoral. Histological examination of the resected material revealed typical gouty tophi (fig 1B). After surgery, he was treated with allopurinol and colchicine. To treat hypertension, he received furosemide and losartan; this latter drug was chosen because it has been shown to have uricosuric properties ${ }^{5}$ and has proved to be beneficial in hypertensive gouty subjects. ${ }^{6}$

\section{Patient 2}

A 25 year old woman who received a transplant in 1996 for type 1 A glycogen storage disease has been treated with tacrolimus since then. Attacks of podagra and arthritis of the left wrist occurred 5 years later when she was receiving tacrolimus $4 \mathrm{mg} / \mathrm{day}$. No tophi could be seen. The serum level of uric acid was $452 \mu \mathrm{mol} / \mathrm{l}$ and of creatinine $190 \mu \mathrm{mol} / \mathrm{l}$. From the time of diagnosis she has been receiving allopurinol $100 \mathrm{mg} /$ day, and the attacks of gout have resolved.

\section{DISCUSSION}

In a large series of patients who had received a liver allograft, hyperuricaemia was detected in about half, in both cyclosporin and tacrolimus treated patients. ${ }^{4}$ It was assumed that both drugs can impair renal uric acid excretion. ${ }^{3}{ }^{4}$

In our series of liver transplant recipients receiving tacrolimus, gout was directly related to tacrolimus treatment in two. In case No 1, large tophaceous deposits developed 

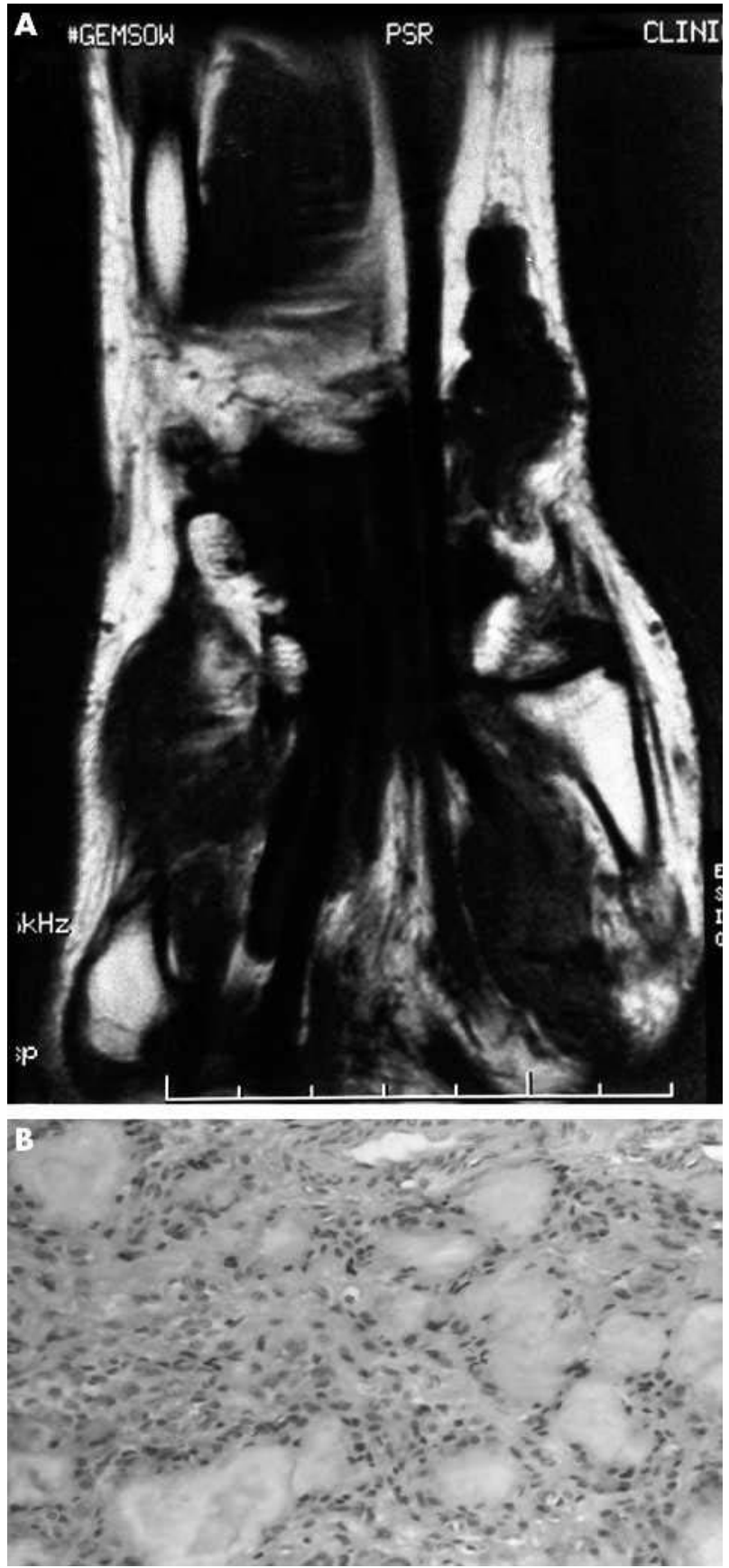

Figure 1 (A) Magnetic resonance $T_{1}$ coronal view showing a polylobed mass of low signal intensity in the radial aspect of the wrist. (B) Histological picture of the mass: large amorphous areas of monosodium urate crystal deposits surrounded by macrophages and giant cells (haematoxylin and eosin $\times 20$ ). very quickly within an interval of 8 months. The same observation has been frequently made with cyclosporin. ${ }^{12}$ Although that patient was also taking diuretics, the causal relationship between tophaceous gout and tacrolimus treatment seems very probable. In case No 2 , it is unlikely that her glycogen storage disease could have been a favouring factor for gout because liver transplantation cures the metabolic abnormalities associated with such disease. ${ }^{7}$

Although no case of gout has been found in the series of patients receiving liver transplants reported by Taillandier et $a l,{ }^{8}$ gout was diagnosed in $6 \%$ of the series of Neal et al. ${ }^{4}$ Although until now cyclosporin has been considered to be the main cause of gout in transplant recipients, our study supports the idea that tacrolimus can similarly induce gout. It appears important to recognise that tacrolimus is a drug favouring hyperuricaemia and gout in some transplant patients, even if probably less likely than cyclosporin. Being aware of this possibility is important so that gout can be treated as early as possible to avoid occurrence of dramatic tophaceous gout, as illustrated in one of our cases.

\section{ACKNOWLEDGEMENTS}

We thank Dr L Guillou of the Institut Universitaire de Pathologie, CHUV, Lausanne, for the histological examinations.

\section{Authors' affiliations}

J C Gerster, M Dudler, Department of Rheumatology, University Hospital (CHUV), Lausanne, Switzerland

N Halkic, M Gillet, Department of Surgery, University Hospital (CHUV), Lausanne, Switzerland

Correspondence to: Professeur J C Gerster, Service de Rhumatologie, CHUV, 1011 Lausanne, Switzerland; Jean-Charles.Gerster@chuv. hospvd.ch

Accepted 24 August 2003

\section{REFERENCES}

1 Lin HY, Rocher LL, McQuillan MA, Schmaltz S, Palella T, Fox IH. Cyclosporineinduced hyperuricemia and gout. N Engl J Med 1989;321:287-92.

2 George T, Mandell BF. Gout in the transplant patient. J Clin Rheumatol 1995; 1:328-34.

3 Van Thiel DH, lqbal M, Jain A, Fung J, Todo S, Starzl TE. Gastrointestinal and metabolic problems associated with immunosuppression with either CyA or FK 506 in liver transplantation. Transplant Proc 1990;22:37-50.

4 Neal DA, Tom BD, Gimson AE, Bibbs P, Alexander GJ. Hyperuricemia, gout, and renal function after liver transplantation. Transplantation 2001;72:1689-91.

5 Minghelli G, Seydoux C, Goy JJ, Burnier M. Uricosuric effect of the angiotensin II receptor antagonist losartan in heart transplant recipients. Transplantation 1998;66:268-71.

6 Würzner G, Gerster JC, Chiolero A, Maillard M, Fallab-Stubi CL, Brunner HR, et al. Comparative effects of losartan and irbesartan on serum uric acid in hypertensive patients with hyperuricaemia and gout. $J$ Hypertens 2001;19:1855-90.

7 Matern D, Starzl TE, Arnaout W, Barnard J, Bynon JS, Dhawan A, et al. Liver transplantation for glycogen storage disease types I, III and IV. Eur J Pediatr 1999; 158(Suppl 2):S43-8.

8 Taillandier J, Alemanni M, Lioté F, Rucay P, Samuel D, Bismuth H. Serum uric acid and liver transplantation. Transplant Proc 1995;27:2108-90. 